\title{
An epidemiological appraisal of the association between heart rate variability and particulate air pollution: a meta-analysis
}

\author{
Nicky Pieters, ${ }^{1}$ Michelle Plusquin, ${ }^{1}$ Bianca Cox, ${ }^{1}$ Michal Kicinski, ${ }^{1}$ Jaco Vangronsveld, ${ }^{1}$ \\ Tim S Nawrot ${ }^{1,2}$
}

- Additional materials are published online only. To view these files please visit the journal online (http://heart.bmi. com/content/98/15.toc).

${ }^{1}$ Centre for Environmental Sciences, Hasselt University, Diepenbeek, Belgium 2Department of Public Health, Occupational \& Environmental Medicine, Leuven, Belgium

\section{Correspondence to}

Professor Tim Nawrot, Hasselt University, Agoralaan Gebouw D, 3590 Diepenbeek, Belgium; tim.nawrot@uhasselt.be

Received 12 December 2011 Revised 11 April 2012 Accepted 12 April 2012 Published Online First 23 May 2012

\section{UNLCKED}

This paper is freely available online under the BMJ Journals unlocked scheme, see http:// heart.bmi.com/site/about/ unlocked.xhtml

\begin{abstract}
Objective Studies on the association between shortterm exposure to ambient air pollution and heart rate variability (HRV) suggest that particulate matter (PM) exposure is associated with reductions in measures of $\mathrm{HRV}$, but there is heterogeneity in the nature and magnitude of this association between studies. The authors performed a meta-analysis to determine how consistent this association is.
\end{abstract}

Data source The authors searched the Pubmed citation database and Web of Knowledge to identify studies on HRV and PM.

Study selection of the epidemiologic studies reviewed, 29 provided sufficient details to be considered. The meta-analysis included 18667 subjects recruited from the population in surveys, studies from patient groups, and from occupationally exposed groups.

Data extraction Two investigators read all papers and computerised all relevant information.

Results The authors computed pooled estimates from a random-effects model. In the combined studies, an increase of $10 \mu \mathrm{g} / \mathrm{m}^{3}$ in $\mathrm{PM}_{2.5}$ was associated with significant reductions in the time-domain measurements, including low frequency $(-1.66 \%, 95 \% \mathrm{Cl}-2.58 \%$ to $0.74 \%)$ and high frequency $(-2.44 \%, 95 \% \mathrm{Cl}-3.76 \%$ to $-1.12 \%$ ) and in frequency-domain measurements, for SDNN $(-0.12 \%, 95 \% \mathrm{Cl}-0.22 \%$ to $-0.03 \%)$ and for rMSSD $(-2.18 \%, 95 \% \mathrm{Cl}-3.33 \%$ to $-1.03 \%)$. Funnel plots suggested that no publication bias was present and a sensitivity analysis confirmed the robustness of our combined estimates

Conclusion The meta-analysis supports an inverse relationship between HRV, a marker for a worse cardiovascular prognosis, and particulate air pollution.

\section{INTRODUCTION}

A recent scientific report from the American Heart Association concluded that particulate matter (PM) is a modifiable risk factor contributing to cardiovascular morbidity and mortality. ${ }^{1}$ We provided a novel insight that particulate air pollution is a relevant trigger for myocardial infarction at the community level. ${ }^{2-4}$ Altered cardiac autonomic function as measured by heart rate variability (HRV) is considered to be one of the pathophysiological pathways through which PM air pollution influences the cardiovascular system. ${ }^{5}{ }^{6}$ Reduced HRV has been associated with an increased risk of myocardial infarction among the population ${ }^{7}$ and has been considered as a predictor of increased risk of mortality in patients with heart failure. ${ }^{8}$ The importance of this pathway is still under debate..$^{910}$ Here we determine whether all the available observational data up to February 2012 support a positive association and how strong such a relationship between $\mathrm{HRV}$ and particulate air pollution may be.

\section{METHODS}

\section{Data collection}

We followed published guidelines for the reporting of this meta-analysis. ${ }^{11}$ A systematic literature search of PubMed and Web of Knowledge, last accessed on 15 February 2012, was conducted to identify studies of HRV and air pollution published in English. In addition, we screened the reference list of all identified relevant publications and review articles found during our literature search. Two search terms were combined using the Boolean operator AND. The first term, air pollution, combined exploded versions of the Medical Subject Headings air pollution, particulate matter and air pollutants. The second term was heart rate variability.

\section{Study selection}

Two investigators (NP and MP) read all papers and extracted and computerised the relevant information independently (table 1). Reviews, case-reports, pilot studies, animal studies, manuscripts not written in English and studies that reported another association were excluded. Out of 509 initially selected articles, 98 studies reported an association between HRV and air pollution. If a group published two or more papers based on the same study population $(\mathrm{n}=31)$, only that publication providing the most detailed information was included. We selected only studies that used particulate matter with aerodynamic diameter of $10 \mu \mathrm{m}$ or less $\left(\mathrm{PM}_{10}\right)$ or $2.5 \mu \mathrm{m}$ or less $\left(\mathrm{PM}_{2.5}\right)$ as indicators of air pollution. Studies were also excluded when a controlled exposure was used. Where applicable, preference was given to results adjusted for age and heart rate and additional factors of proven importance. ${ }^{40}$ Quality assessment of the selected studies was performed with consideration of the following aspects: study design, response rate, information about responders versus non-responders, sample size, statistical methods, correction for meteorological conditions and personal or local PM assessment (supplementary data).

\section{Statistical analysis}

HRV was evaluated using different time-domain and frequency-domain measures, according to the 


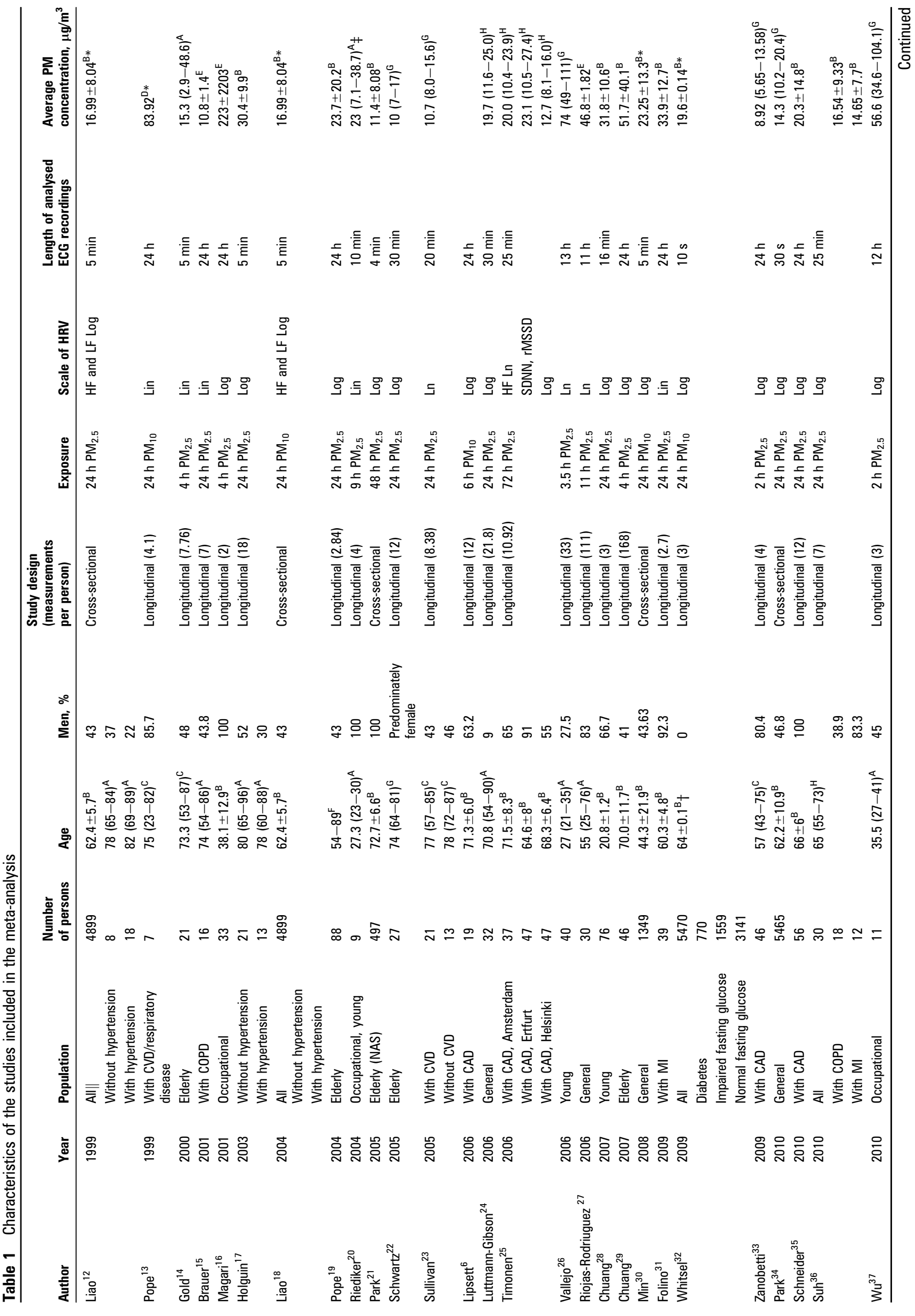


measurements presented in the included studies. The timedomain measures include rMSSD, the square root of the mean squared difference of successive normal to normal intervals, and SDNN, the SD of the normal to normal intervals. Two spectral components were distinguished in the frequency-domain measurements: low frequency (LF) power and high frequency (HF) power. Many time- and frequency-domain variables measured over a 24-h ECG recording are strongly correlated with each other. ${ }^{41}$ We obtained a meta-analytical effect estimate using random-effects models, because the Cochran Q-statistics showed evidence of heterogeneity greater than expected by the sampling variance alone $(p<0.1)$. An effect estimate was derived from the point estimate of each separate study weighted by the inverse of the variance $\left(1 / \mathrm{SE}^{2}\right)$. When we had independent subgroups within a study, each subgroup was treated as a separate study. The effect size was calculated as a per cent change for an exposure increment of $10 \mu \mathrm{g} / \mathrm{m}^{3}$ in $\mathrm{PM}_{2.5}$. The per cent change was calculated as $\left(10^{\wedge} \beta-1\right) \times 100 \%$ with $95 \%$ CIs $\left(\left(10^{\wedge}(\beta \pm 1.96 \times \mathrm{SE})\right)-1\right) \times 100 \%$, where $10^{\mathrm{X}}$ is the antilog, $\beta$ is the estimated regression coefficient and SE is the SE of $\beta$, when HRV was log-transformed. The formula $(1-$ (Average- $\beta) /$ Average $) \times$ $100 \%$ was used when there was no transformation. When data for only $\mathrm{PM}_{10}$ were available, ${ }^{6} 133032$ we converted the per cent change with the assumption that $\mathrm{PM}_{10}$ consists of $70 \%$ of $\mathrm{PM}_{2.5}{ }^{2}{ }^{42}$ However, other conversions were considered in sensitivity analysis to determine what the effect would be on the overall estimate, supposing $\mathrm{PM}_{10}$ consists of $60 \%$ or $80 \%$ of $\mathrm{PM}_{2.5}{ }^{2}$ All calculations were independently performed by two researchers (NP and $\mathrm{MP}$ ).

Sensitivity of the findings was examined by performing the analysis both with and without the occupational studies. ${ }^{16} 2037$ The analysis was repeated separately for long-term (more than $18 \mathrm{~h}$ of analysable ECG recordings) and short-term $(<1 \mathrm{~h}$ of analysable ECG recordings) ECG recordings. Three studies 262737 could not be classified according to this distinction and were excluded from the short- and long-term analyses. We determined whether there was a difference in the combined effect size when only studies with a high quality score were included. We also tested the difference between a 24-h exposure and 48-h exposure on the HRV. Since both $24 \mathrm{~h}$ and $48 \mathrm{~h}$ measurements were used in some of these studies ${ }^{1321252830}$, the effect size for the $48 \mathrm{~h}$ exposure, used in the sensitivity analysis, differed from the data given in table 1, figures 1 and 2. Further, we evaluated the influence of individual studies on pooled effect sizes by excluding one study at the time. If the point estimate of the combined effect size with one study omitted lies outside the $\mathrm{CI}$ of the overall estimate, the study in question has an excessive influence. We plotted the association size against the SE of the study. If there is no publication bias, such a plot must produce a funnel shape (funnel plot), because the points scatter around the true pooled value with the scattering narrowing as the sample size increases. All $p$ values are two-sided tests.

A meta-regression was performed to investigate the effect of study design (longitudinal vs cross-sectional), mean age, mean $\mathrm{PM}_{2.5}$ concentration, scale of HRV (log vs linear), percentage of men, year of publication and length of analysed ECG recordings on the combined effect of $\mathrm{PM}_{2.5}$ on HRV.

\section{RESULTS}

\section{Selection of studies}

Of the studies reviewed 480 reports were excluded; 128 were duplicates, 174 were excluded based on screening the abstract, 24 studies were reviews, 57 studies reported on animal data, one study was a pilot-study, four publications were not written in 
English, one study was a case report, 20 studies reported another association than PM and HRV, 19 studies with an estimated exposure from other measurements than the particulate air pollution $\left(\mathrm{PM}_{10}\right.$ or $\left.\mathrm{PM}_{2.5}\right)$, two did not provide sufficient information to compute the association size, 17 were experimental studies, 31 used the same study population as reports included in the analysis and two studies used PM measurements longer than $24 \mathrm{~h}$ (supplementary data). As a result, we identified 29 studies, comprising 18667 persons, which investigated the association between HRV and PM. This selection includes 25 longitudinal studies, ${ }^{6}$ 12-17 19-29 31-33 35-39 including one exploratory study ${ }^{15}$ and three occupational studies ${ }^{16} 2037$ and four cross-sectional designs. $^{18} 21 \quad 3034$ These are listed in chronological order in table 1.

\section{Characteristics of studies}

All studies had a time window of PM measurements ranging from $2 \mathrm{~h}$ up to 1 day before HRV measurements. The length of ECG recordings varied from $10 \mathrm{~s}$ to $24 \mathrm{~h}$. Whenever possible, preference was given to long-term ECG recordings (more than $18 \mathrm{~h}$ of analysable ECG recordings). The HRV measurements were expressed on a logarithmic scale in 23 studies $^{6} 12$ 16-19 21-30 32-37 39 and on a linear scale in five studies. ${ }^{13-152031}$ One publication used both a linear and logarithmic scale. ${ }^{38}$

Only one study calculated the association between PM exposure and HRV without reporting possible confounders. ${ }^{15}$ One study included potential confounders but did not report them. ${ }^{20}$ In all but four reports ${ }^{19} 253135$ the results were adjusted for age.
Eleven publications did not adjust for sex. ${ }^{16} 213235$ However, in four $^{16} 213235$ of these 11 reports, all subjects had the same sex. Most studies also considered additional confounding variables such as heart rate, ${ }^{13} 16-1922333739$ BMI, ${ }^{14} 18212628293234-3639$ outdoor temperature, ${ }^{14} 181921-3436-39$ relative humidity, ${ }^{14} 18-21$ 23-3133 34 36-39 ethnicity $^{14182432-3438}$ and (past) smoking. ${ }^{16} 1821$ $30-35$

\section{Summary statistics}

We evaluated HRV using both frequency- and time-domain measurements. The combined estimates calculated for a $10 \mu \mathrm{g} /$ $\mathrm{m}^{3}$ increase in $\mathrm{PM}_{2.5}$ showed a decrease of $1.66 \%(95 \% \mathrm{CI}$ $-2.58 \%$ to $-0.74 \%$ ) and $2.44 \%$ (95\% CI $-3.76 \%$ to $-1.12 \%$ ) for LF and HF, respectively. The corresponding estimates for the time-domain measurements were $-0.12 \%(95 \% \mathrm{CI}-0.22 \%$ to $-0.03 \%)$ for SDNN and $-2.18 \%(95 \% \mathrm{CI}-3.33 \%$ to $-1.03 \%)$ in rMSSD (figure 1).

\section{Sensitivity analysis}

When the analysis was repeated without three occupational studies, ${ }^{16} 2037$ we found a minor difference in LF, $-2.05 \%(95 \%$ CI $-3.21 \%$ to $-0.88 \%)$ and $\mathrm{HF},-3.17 \%$ (95\% CI $-4.92 \%$ to $-1.41 \%$ ) for a $10 \mu \mathrm{g} / \mathrm{m}^{3}$ increase in $\mathrm{PM}_{2.5}$ (figure 2). However, the effect of exclusion of these three studies was much larger for SDNN, which results in a combined effect of $-1.25 \%(95 \% \mathrm{CI}$ $-1.81 \%$ to $-0.68 \%$ ).

For LF and HF the majority of studies, $75 \%$ and $71 \%$ respectively, used short-term ECG recordings. When removing the
Figure 1 Forests plots of change in parameter $(95 \% \mathrm{CI})$ of heart rate variability associated with a $10 \mu \mathrm{g} / \mathrm{m}^{3}$ increase in $\mathrm{PM}_{2.5}$ with inclusion of occupational studies. Squares represent individual groups. The area of each square is proportional to the inverse of the variance. $H F$, high frequency; $L F$, low frequency; $\mathrm{PM}_{2.5}$, particulate matter with aerodynamic diameter of $2.5 \mu \mathrm{m}$ or less; rMSSD, square root of the mean squared difference of successive normal to normal intervals; SDNN, SD of normal to normal intervals.
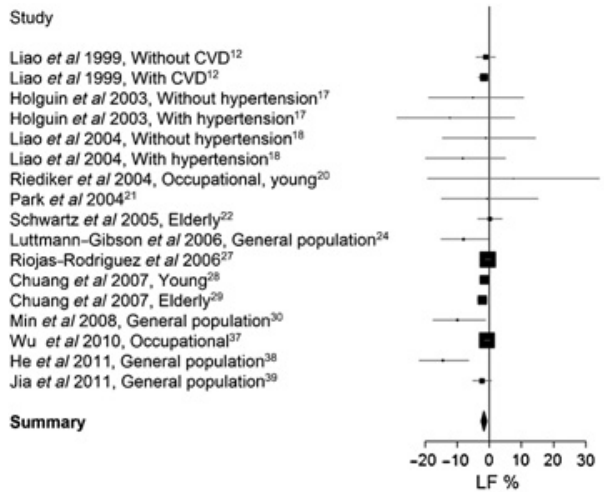

Study

Liao et al 1999, Without CVD
Liao et al 1999, With CVD Holguin et al 2003, Without hypertension 17 Holguin et a/ 2003, With hypertension

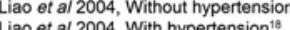
Riediker et al 2004, Occupational, young 2 Park et al $2004^{21}$ Sullivan et al 2005, With CVD 23 Sullivan et a/ 2005, Without CVD 23 Luttmann-Gibson et al. 2006, General population Timonen et al 2006 With $\mathrm{CAD}^{23}$ Riojas-Rodriguez et al $2006^{27}$ Chuang et al 2007 , Young ${ }^{20}$ Chuang et al 2007, Young Min et al 2008 , General population Zanobetti et al 2009. With CAD 3 Wu et al 2010 . Occupationa He et al 2011, General population Jia et al 2011, General population ${ }^{39}$ Summary
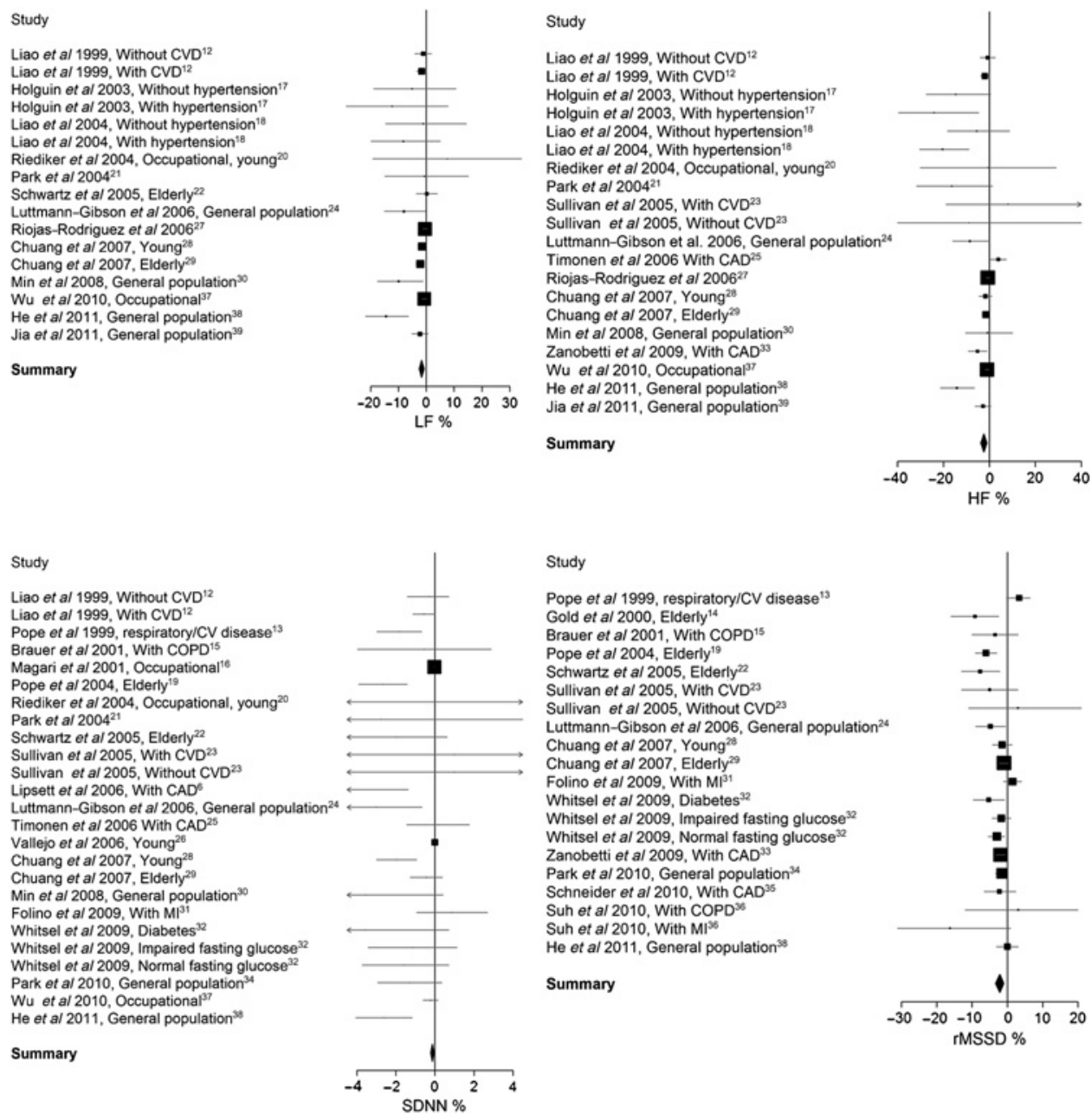
Figure 2 Change in parameter $195 \%$ Cl) of heart rate variability associated with a $10 \mu \mathrm{g} / \mathrm{m}^{3}$ increase in $\mathrm{PM}_{2.5}$ without inclusion of occupational studies. Squares represent individual groups. The area of each square is proportional to the inverse of the variance. $H F$, high frequency; $L F$, low frequency; $\mathrm{PM}_{2.5}$, particulate matter with aerodynamic diameter of $2.5 \mu \mathrm{m}$ or less; rMSSD, square root of the mean squared difference of successive normal to normal intervals; SDNN, SD of normal to normal intervals.
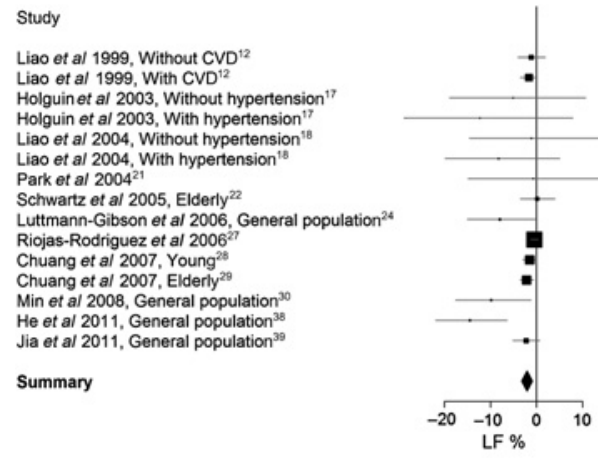

Study

Liao et al 1999, Without CVD With CVD Holguin et al 2003, Without hypertension ${ }^{17}$ Holguin et al 2003, With hypertension ${ }^{17}$

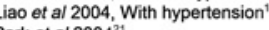
(1) With CVD ${ }^{23}$ Sul al 2005, Without CVD ${ }^{23}$ (2) Timonen et al 2006 With $\mathrm{CAD}^{25}$ Riojas-Rodriguez et al $2006^{27}$ Chuang et al 2007 Y Young ${ }^{28}$ Chuang et al 2007. Elderly $y^{29}$ Min et al 2008 General popula Zanobetti et al 2009. With CAD 33 He al 2011, Jia et al 2011, General population Summary

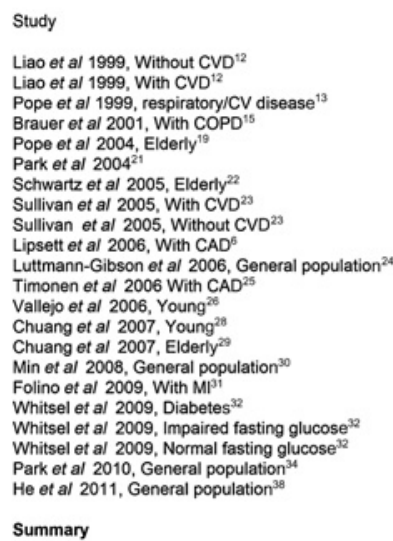

Summary

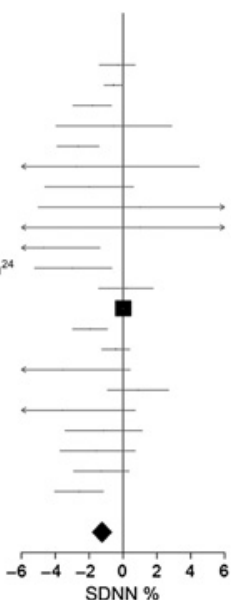

Study

Pope et al 1999, respiratory/CV disease' Gold et al 2000, Elderly" Brauer et al 2001, With COPD" Pope et al 2004, Elderly ${ }^{19}$ Schwartz et al 2005, Elderly ${ }^{22}$ Sullivan et al 2005, With CVD ${ }^{23}$ Sullivan et al 2005, Without CVD Luttmann-Gibson et al 2006, General population ${ }^{24}$ Chuang et al 2007, Youngas Chuang et al 2007, Elderly Folino et al 2009, With Mip Whitsel et al 2009, Diabetes Whing glucose $e^{x}$ Whitsel et al 2009, Normal fasting glucose Zanobetti et al 2009, With CAD ark et al 2010, General population ${ }^{3}$ Schneider et al 2010, With CADS Suh et al 2010, With cop Cin He et al 2011, General population ${ }^{39}$ Summary

estimate outside the CI for the overall estimate with all available studies, including the occupational studies. Recalculating the per cent change, supposing that $\mathrm{PM}_{10}$ consists of $60 \%$ or $80 \%$ of $\mathrm{PM}_{2.5}$, to determine what the effect would be on the overall estimate did not have a significant influence on the overall estimate (data not shown).

\section{Publication bias}

The funnel plots searching for publication bias (supplementary data) did not reveal a deficit of small studies with negative results. Meta-regression revealed that study design (longitudinal vs cross-sectional), mean age, mean $\mathrm{PM}_{2.5}$ concentration, scale of HRV (log vs linear), percentage of men, year of publication and length of analysed ECG did not have a significant influence on the combined estimates; with exception for LF domain, the effects tended to be less strong in logarithmic studies $(p=0.05)$ and stronger in studies with more men $(p=0.04)$. For HF, the effects tended to be less strong for younger persons $(p=0.03)$. $-4.32 \%$ to $-0.36 \%)$ and $\mathrm{HF}(-5.74 \%, 95 \%$ CI $-8.82 \%$ to $-2.66 \%)$, similar for rMSSD (-1.89\%, 95\% CI -3.08 to $-0.71 \%)$ but was no longer significant for SDNN $(-0.05 \%$, 95\% CI $-0.13 \%$ to $0.02 \%$ ). When determining the effect of a $48-\mathrm{h}$ exposure, we found a similar decrease in LF, HF and SDNN.

Also, when four studies ${ }^{18} 213034$ with a cross-sectional design were excluded the combined effect estimate was comparable (table 2). When studies with $\mathrm{PM}_{10}$ measurements were excluded from the analysis, the results were similar for all HRV parameters (table 2). The sensitivity of the findings was further examined by removing one study at a time from the analysis and recalculating the combined effect (supplementary data). For SDNN, we identified two studies ${ }^{16} 26$ that moved the point

\section{DISCUSSION}

The key finding of the present meta-analysis was that HRV by means of SDNN, rMSSD, HF and LF was decreased after an elevation in exposure to particulate air pollution $\left(\mathrm{PM}_{2.5}\right)$ of $10 \mu \mathrm{g} / \mathrm{m}^{3}$. These effects were calculated using 29 studies that met the inclusion criteria comprising 18667 study participants. We did not observe statistical evidence that the combined effect estimates were largely driven by the three occupational studies.

A reduced HRV is a powerful and independent predictor of adverse prognosis in patients with heart disease $e^{43-45}$ and in the general population. ${ }^{46} 47$ It is a marker of cardiac autonomic 
Table 2 Sensitivity analysis

\begin{tabular}{|c|c|c|c|c|c|}
\hline HRV parameter & $\begin{array}{l}\text { Number of } \\
\text { studies included }\end{array}$ & $\begin{array}{l}\text { Number of } \\
\text { subjects included }\end{array}$ & $\begin{array}{l}\text { Combined } \\
\text { estimate }(95 \% \mathrm{Cl})\end{array}$ & $\begin{array}{l}\text { p Value for } \\
\text { Cochran 0-statistics }\end{array}$ & $\begin{array}{l}I^{2} \text { degree of } \\
\text { heterogeneity }(\%)\end{array}$ \\
\hline \multicolumn{6}{|l|}{ LF } \\
\hline All & 14 & 7172 & $-1.66(-2.58$ to -0.74$)$ & 0.02 & 45.0 \\
\hline $\begin{array}{l}\text { Excluding studies with long-term } \\
\text { ECG measurements }\end{array}$ & 9 & 6949 & $-1.73(-2.73$ to -0.73$)$ & 0.4618 & 0.0 \\
\hline $\begin{array}{l}\text { Excluding groups with patients suffering from } \\
\text { cardiovascular disease }\end{array}$ & 16 groups & 7154 & $-1.71(-2.74$ to -0.68$)$ & 0.0178 & 47.7 \\
\hline Excluding studies with $\mathrm{PM}_{10}$ measurements & 11 & 924 & $-1.48(-2.35$ to -0.61$)$ & 0.0373 & 44.4 \\
\hline Excluding studies with a low quality score & 8 & 6532 & $-2.49(-4.36$ to -0.62$)$ & 0.0121 & 57.4 \\
\hline \multicolumn{6}{|l|}{$\mathrm{HF}$} \\
\hline All & 16 & 7356 & $-2.44(-3.76$ to -1.12$)$ & $<0.0001$ & 66.7 \\
\hline Excluding occupational studies & 14 & 7336 & $-3.17(-4.92$ to -1.41$)$ & $<0.0001$ & 70.1 \\
\hline $\begin{array}{l}\text { Excluding studies with long-term ECG } \\
\text { measurements }\end{array}$ & 10 & 7087 & $-1.75(-3.20$ to -0.29$)$ & 0.0005 & 62.3 \\
\hline Excluding studies with $\mathrm{PM}_{10}$ measurements & 14 & 1108 & $-2.04(-3.26$ to -0.82$)$ & 0.0002 & 63.9 \\
\hline Excluding studies with a low quality score & 9 & 6585 & $-5.74(-8.82$ to -2.66$)$ & $<0.0001$ & 71.8 \\
\hline \multicolumn{6}{|l|}{ SDNN } \\
\hline All & 21 & 13521 & $-0.12(-0.22$ to -0.03$)$ & $<0.0001$ & 74.0 \\
\hline Excluding occupational studies & 18 & 13468 & $-1.25(-1.81$ to -0.68$)$ & $<0.0001$ & 76.1 \\
\hline $\begin{array}{l}\text { Excluding studies with long-term } \\
\text { ECG measurements }\end{array}$ & 11 & 13167 & $-0.73(-1.17$ to -0.29$)$ & 0.0006 & 60.7 \\
\hline $\begin{array}{l}\text { Excluding studies with short-term } \\
\text { ECG measurements }\end{array}$ & 8 & 354 & $-1.39(-2.37$ to -0.41$)$ & $<0.0001$ & 84.5 \\
\hline $\begin{array}{l}\text { Excluding groups with patients suffering } \\
\text { from cardiovascular disease }\end{array}$ & 19 groups & 13286 & $-0.08(-0.17$ to 0.004$)$ & $<0.0001$ & 74.5 \\
\hline Excluding studies with a cross-sectional design & 18 & 6210 & $-0.11(-0.21$ to -0.02$)$ & $<0.0001$ & 75.6 \\
\hline Excluding studies with $\mathrm{PM}_{10}$ measurements & 17 & 6595 & $-0.07(-0.14$ to 0.005$)$ & $<0.0001$ & 69.2 \\
\hline $\begin{array}{l}\text { Excluding groups with patients suffering } \\
\text { from cardiovascular disease }\end{array}$ & 14 groups & 11256 & $-2.78(-4.03$ to -1.52$)$ & 0.022 & 48.3 \\
\hline Excluding studies with a cross-sectional design & 15 & 5972 & $-2.29(-3.56$ to -1.02$)$ & 0.0004 & 60.0 \\
\hline Excluding studies with $\mathrm{PM}_{10}$ measurements & 15 & 11349 & $-1.86(-2.96$ to -0.76$)$ & 0.0051 & 51.5 \\
\hline Excluding studies with a low quality score & 9 & 11293 & $-1.89(-3.08$ to -0.71$)$ & 0.0643 & 40.4 \\
\hline
\end{tabular}

HF, high frequency; HRV, heart rate variability; LF, low frequency; $\mathrm{PM}_{10}$, particulate matter with aerodynamic diameter of $10 \mu \mathrm{m}$ or less; rMSSD, square root of the mean squared difference of successive normal to normal intervals; SDNN, SD of normal to normal intervals.

dysfunction and a predictor of sudden cardiac death and arrhythmias. $^{8}$ A reduction of HRV has been reported in several cardiological and non-cardiological diseases such as myocardial infarction, diabetic neuropathy, cardiac transplantation, myocardial dysfunction and tetraplegia. ${ }^{8}$ HRV measurements are also promising as risk markers for fatigue, ${ }^{48}$ ageing $^{49}$ and stress-situations. ${ }^{50}$ Despite the important prognostic power of HRV, it is still not a widely used tool in diagnostic settings, and agreed normative values for HRV remain missing. ${ }^{51}$ In terms of clinical significance the association between decreasing HRV with increasing air pollution is still under debate as the decrease in HRV can be a marker of cardiac disease or the cause of increased risk. The underlying mechanisms responsible for the association between fine PM exposure and impaired HRV are not yet fully understood. Substantial epidemiological literature links cardiovascular mortality and morbidity to exposures of ambient air pollution. ${ }^{52}$ Two main candidate mechanisms are release of pro-thrombotic and inflammatory cytokines from the lung, and effects on the electrical activity and autonomic function of the heart. ${ }^{54} \mathrm{HRV}$ is indicative for the physiological responses of the autonomic nervous system, of the combined sympathetic and parasympathetic activity. Alterations in autonomic control of the heart, as represented by HRV, may represent a major pathophysiological mechanism by which air pollution leads to cardiac mortality. ${ }^{55}$ Two possible pathways can lead to changes in neural control of the heart affecting HRV by exposure to PM. ${ }^{55}$ Inhaled particles can promote a systemic sympathetic stress response that leads to decreased HRV measurements and may cumulate in ventricular tachyarrhythmia. On the other hand, the inhaled particles can stimulate irritant receptors in the lung parenchyma and respiratory airways, which leads to the opposite, an increased parasympathetic vagal response and increased HRV. ${ }^{55}$ Our combined estimate showed a decrease in all HRV parameters, which suggests an overall sympathetic 
response. The combined effect was most pronounced for HF, which is highly correlated with rMSSD. ${ }^{13}$ They both reflect parasympathetic cardial vagal tone. A decrease in SDNN, an overall measure of changes in autonomic tone, also implies an increased risk of cardiac morbidity and mortality.

Dietrich et al ${ }^{56}$ measured the effect of ETS on HRV through 24-h ECG recordings in 1218 non-smokers aged $\geq 50$ years. Individuals who were passively exposed to environmental tobacco smoke at home or at work for more than $2 \mathrm{~h} /$ day had a decrease of $3.5 \%$ in SDNN, $0.14 \%$ in $\mathrm{HF}$ and $15.35 \%$ in LF. Compared with our meta-analytical estimates on HRV and $\mathrm{PM}_{2.5}$, the effects of passive smoking were more pronounced for SDNN and LF as these effects were $-0.12 \%$ and $-1.66 \%$ for a $10 \mu \mathrm{g} / \mathrm{m}^{3}$ increase in $\mathrm{PM}_{2.5}$. For HF, the effect for PM was more pronounced; we found an effect of $-2.44 \%$. We should be aware that $\mathrm{PM}$ exposure is a continuous variable and the expression for a $10 \mu \mathrm{g} / \mathrm{m}^{3}$ increase is a relatively small increase, as a difference of $30 \mu \mathrm{g} / \mathrm{m}^{3}$ in acute exposure is still within the range of daily variation in many parts of the world. ${ }^{2}$

Since air particulates can provoke oxidative stress and an inflammatory response in the lung and heart, ${ }^{57}$ oxidative stress is a potentially important cellular mechanism. A study by Schwartz et al ${ }^{58}$ concluded that the effects of $\mathrm{PM}_{2.5}$ on $\mathrm{HF}$ seemed to be mediated by reactive oxygen. The Normative Aging Study has shown a strong effect modification of the PM and HRV relationship by obesity and genes that modulate endogenous oxidative stress or xenobiotic metabolism, such as glutathione S-transferase M1, methylenetetrahydrofolate reductase and the haemochromatosis gene. ${ }^{58-60}$ Additional findings suggest protective effects of statins, dietary antioxidants and B vitamins, as well as $\omega-3$ polyunsaturated fatty acids. $^{58} 596162$ These findings imply that pathways that decrease endogenous oxidative stress have a protective effect that alleviates reductions in HRV due to exposure of particulate air pollution. An alternative potential mechanism is provided by Schulz et $a l^{63}$ who found that an altered ion-channel function triggered by air pollution in myocardial cells can lead to cardiac malfunction.

Observational studies as included in our meta-analysis do not prove causation. However, repeated observation of an association in different populations and different subgroups showing the same or similar results suggest that the results of a single study are not due to coincidence. Our forest plots showed that the majority of studies showed a decrease in parameters of HRV in association with particulate air pollution. We showed consistent results between different study designs including cross-sectional studies, panel and repeated measure studies, which support a causal association. Furthermore, we observed heterogeneity between studies but our estimates were robust. Although in general the average concentration of occupational $\mathrm{PM}_{2.5}$ exposure was much higher than environmental exposure, exclusion of three occupational studies ${ }^{16} 2037$ did not alter the combined estimate.

Although most studies report negative associations between time- or frequency-domain parameters of HRV and particulate air pollution, the magnitudes of the effect differ among these studies. We addressed the issue of heterogeneity between studies by computing pooled estimates from a random-effects model. Differences in magnitude between studies may be due to variation in the composition of PM or length of ECG recordings but also by including subgroups of populations on antiinflammatory drugs or lacking anti-inflammatory defence $\left(\right.$ GSTM null ${ }^{58}$ ). The effects of $\mathrm{PM}_{2.5}$ likely vary depending on pollution sources and particulate constituents; indeed, a multi- centre study by Timonen et $a l^{25}$ found that the effects of PM on HRV were dependent on local sources of PM. Increases in $\mathrm{PM}_{2.5}$ concentration were associated with decreases in HF in Helsinki, but a similar increase in $\mathrm{PM}_{2.5}$ was associated with an increase in $\mathrm{HF}$ in Ertfurt. Although a 5-min measurement is recommended and highly reproducible, ${ }^{8} 30$ the $24-\mathrm{h}$ measurement includes the nocturnal period during which people in general have a very different autonomic regulation and which is mainly driven by the parasympathetic component. ${ }^{64}$ However, when we performed a separate analysis for long-term and short-term recordings, we found a decrease for SDNN and $\mathrm{MSSD}$ in both short-term and long-term recordings, although the decrease in long-term recording for rMSSD was statistically not significant $(p=0.21)$. Differences between studies in the HRV particulate air pollution association might also be explained by differences in the disease status of the subjects. Various disease processes (myocardial infarction, diabetes, chronic obstructive pulmonary disease) as well as physiological conditions, including ageing, ${ }^{65}$ and drugs ( $\beta$-blockers) alter autonomic control, and therefore change the HRV. However, when the study groups with subjects suffering from cardiovascular diseases were excluded, the combined estimate did not differ significantly from the effect found when these groups were included. Hence, the association between HRV and PM exposure is not only seen in susceptible subgroups. Contrary to our meta-analysis, a recent experimental study ${ }^{9}$ found no effects of dilute diesel exhaust inhalation for $1 \mathrm{~h}$ on heart rhythm and HRV in healthy volunteers or in an 'at-risk' population of patients with stable coronary heart disease. Explanations for the discrepancy between these epidemiological data and negative results in controlled conditions may include too short exposure and difference pollution mixture. Indeed, most of the observational studies included an exposure window of $24 \mathrm{~h}$. On the other hand, in the observational studies confounding or residual confounding by ambient temperature cannot be excluded. Of the included studies in our meta-analysis, 20 (69\%) adjusted for meteorological conditions (see supplementary table 1).

To determine whether the combined effect is influenced by a particular publication, a sensitivity analysis was performed. HRV parameters were not strongly determined by one study.

Our main analysis included only studies which used a lag of $\leq 24 \mathrm{~h}$ of $\mathrm{PM}_{2.5}$ or $\mathrm{PM}_{10}$ exposure. However, we conducted a separate meta-analysis with studies reporting the effect of a 48-h exposure. ${ }^{1321} 252830$ The combined effect estimate for $48 \mathrm{~h}$ was similar to the effect found for $24 \mathrm{~h}$ when occupational studies were excluded for LF, HF and SDNN. The effect of a 48-h exposure could not be calculated for rMSSD due to the lack of studies reporting rMSSD.

The present results should be interpreted within the context of their limitations. First, the analysis was not adjusted for variation in length of ECG recordings. On the other hand, a sensitivity analysis with the different lengths of the ECGs did not reveal differences in combined effect sizes according to length for LF, HF and SDNN. For rMSSD, the analysis stratified for short- and long-term recordings showed only significant results for short-term recordings. Third, if there was heterogeneity in the reporting strategy between studies, we had to address this issue by calculating the $\beta$-coefficients to percentages and calculated $\mathrm{PM}_{2.5}$ from $\mathrm{PM}_{10}$ by using the formulae as given in the Methods section. Also, different study designs were used in the combined estimate. Nevertheless, in the sensitivity analysis, we confirmed the robustness of the overall estimate by including only panel studies. In other words, the overall estimate was not strongly influenced by the included studies with a cross- 
sectional nature. And last, generally accountable for meta-analysis is a publication bias in that studies with a positive result are more likely to be published than negative results. The funnel plots searching for publication bias did not reveal a deficit of small studies with negative results, suggesting that overall there was no publication bias.

The present meta-analysis shows an overall statistically significant inverse association between parameters of HRV and exposure to particulate air pollution, which might be relevant in biological terms. Indeed, the putative mechanisms of the acute effects of PM include sympathetic activation/parasympathetic withdrawal leading to haemostatic and haemodynamic changes that are recognised to increase the risk of cardiovascular events.

Contributors TN and NP designed the study. NP and MP performed the systematic literature review, constructed the database and analysed the data with help of $\mathrm{BC}$ and MK. NP drafted the first version of the manuscript together with MP and TN. All authors took part in the interpretation of the results and prepared the final version.

Funding The research on air pollution and health at Hasselt University is supported by a grant from the Flemish Scientific Fund (FWO/G.0873.11), tUL-impuls financing and Hasselt University Bijzonder OnderzoeksFonds (BOF). MK has a PhD fellowship of the Research Foundation-Flanders (FWO).

\section{Competing interests None.}

Provenance and peer review Not commissioned; internally peer reviewed.

\section{REFERENCES}

1. Brook RD, Rajagopalan S, Pope CA, et al. Particulate matter air pollution and cardiovascular disease: an update to the scientific statement from the American Heart Association. Circulation 2010:121:2331-78.

2. Nawrot TS, Perez L, Kunzli N, et al. Public health importance of triggers of myocardial infarction: a comparative risk assessment. Lancet 2011;377: 732-40.

3. Baccarelli A, Benjamin EJ. Triggers of Ml for the individual and in the community Lancet 2011;377:694-6.

4. Nawrot TS, Nemmar A, Nemery B. Air pollution: to the heart of the matter. Eur Heart J 2006;27:2269-71.

5. Pope CA 3rd, Dockery DW. Health effects of fine particulate air pollution: lines that connect. J Air Waste Manag Assoc 2006;56:709-42.

6. $\quad$ Lipsett MJ, Tsai FC, Roger L, et al. Coarse particles and heart rate variability among older adults with coronary artery disease in the Coachella Valley, California. Environ Health Perspect 2006;114:1215-20.

7. Sinnreich R, Kark JD, Friedlander $Y$, et al. Five minute recordings of heart rate variability for population studies: repeatability and age-sex characteristics. Heart 1998:80:156-62.

8. Camm AJ, Malik M, Bigger JT, et al. Heart rate variability-standards of measurement, physiological interpretation, and clinical use. Circulation 1996;93:1043-65

9. Mills NL, Finlayson AE, Gonzalez MC, et al. Diesel exhaust inhalation does not affect heart rhythm or heart rate variability. Heart 2011;97:544-50.

10. Bhaskaran K, Wilkinson $P$, Smeeth $L$. Cardiovascular consequences of air pollution: what are the mechanisms? Heart 2011:97:519-20.

11. Stroup DF, Berlin JA, Morton SC, et al. Meta-analysis of observational studies in epidemiology. JAMA 2000;283:2008-12.

12. Liao DP, Creason J, Shy C, et al. Daily variation of particulate air pollution and poor cardiac autonomic control in the elderly. Environ Health Perspect 1999;107:521-5.

13. Pope CA, Verrier RL, Lovett EG, et al. Heart rate variability associated with particulate air pollution. Am Heart J 1999;138:890-9.

14. Gold DR, Litonjua A, Schwartz J, et al. Ambient pollution and heart rate variability. Circulation 2000;101:1267-73.

15. Brauer M, Ebelt ST, Fisher TV, et al. Exposure of chronic obstructive pulmonary disease patients to particles: respiratory and cardiovascular health effects. J Expo Anal Environ Epidemiol 2001;11:490-500.

16. Magari SR, Hauser R, Schwartz J, et al. Association of heart rate variability with occupational and environmental exposure to particulate air pollution. Circulation 2001;104:986-91.

17. Holguín F, Téllez-Rojo MM, Hernández $\mathrm{M}$, et al. Air pollution and heart rate variability among the elderly in Mexico City. Epidemiology 2003;14:521-7.

18. Liao DP, Duan YK, Whitsel EA, et al. Association of higher levels of ambient criteria pollutants with impaired cardiac autonomic control: a population-based study. $A m \mathrm{~J}$ Epidemiol 2004;159:768-77.
19. Pope CA, Hansen ML, Long RW, et al. Ambient particulate air pollution, heart rate variability, and blood markers of inflammation in a panel of elderly subjects. Environ Health Perspect 2004;112:339-45.

20. Riediker M, Cascio WE, Griggs TR, et al. Particulate matter exposure in cars is associated with cardiovascular effects in healthy young men. Am J Respir Crit Care Med 2004:169:934-40.

21. Park SK, O'Neill MS, Vokonas PS, et al. Effects of air pollution on heart rate variability: the VA normative aging study. Environ Health Perspect 2005:113:304-9.

22. Schwartz J, Litonjua $A$, Suh $\mathrm{H}$, et al. Traffic related pollution and heart rate variability in a panel of elderly subjects. Thorax 2005;60:455-61.

23. Sullivan JH, Schreuder AB, Trenga CA, et al. Association between short term exposure to fine particulate matter and heart rate variability in older subjects with and without heart disease. Thorax 2005;60:462-6.

24. Luttmann-Gibson $\mathbf{H}$, Suh HH, Coull BA, et al. Short-term effects of air pollution on heart rate variability in senior adults in Steubenville, Ohio. J Occup Environ Med 2006;48:780-8.

25. Timonen $\mathbf{K L}$, Vanninen E, De Hartog J, et al. Effects of ultrafine and fine particulate and gaseous air pollution on cardiac autonomic control in subjects with coronary artery disease: the ULTRA study. J Expo Sci Environ Epidemiol 2006;16:332-41

26. Vallejo M, Ruiz $\mathrm{S}$, Hermosillo $A G$, et al. Ambient fine particles modify heart rate variability in young healthy adults. J Expo Sci Environ Epidemiol 2006; 16:125-30

27. Riojas-Rodriguez H, Escamilla-Cejudo JA, Gonzalez-Hermosillo JA, et al. Personal PM2.5 and $\mathrm{CO}$ exposures and heart rate variability in subjects with known ischemic heart disease in Mexico City. J Expo Sci Environ Epidemiol 2006;16:131-7.

28. Chuang KJ, Chan CC, Su TC, et al. The effect of urban air pollution on inflammation oxidative stress, coagulation, and autonomic dysfunction in young adults. Am J Respir Crit Care Med 2007;176:370-6.

29. Chuang K-J, Chan C-C, Su T-C, et al. Associations between particulate Sulfate and Organic Carbon exposures and heart rate variability in patients with or at risk for cardiovascular diseases. J Occup Environ Med 2007:49:610-17.

30. Min K-B, Min J-Y, Cho S-I, et al. The relationship between air pollutants and heart-rate variability among community residents in Korea. Inhal Toxicol 2008;20:435-44

31. Folino AF, Scapellato ML, Canova C, et al. Individual exposure to particulate matte and the short-term arrhythmic and autonomic profiles in patients with myocardial infarction. Eur Heart J 2009:30:1614-20.

32. Whitsel EA, Quibrera PM, Christ SL, et al. Heart rate variability, ambient particulate matter air pollution, and glucose homeostasis: the environmental epidemiology of arrhythmogenesis in the women's health initiative. Am J Epidemiol 2009;169:693-703

33. Zanobetti A, Gold DR, Stone PH, et al. Reduction in heart rate variability with traffic and air pollution in patients with coronary artery disease. Environ Health Perspect 2009; 118:324-30.

34. Park SK, Auchincloss AH, O'Neill MS, et al. Particulate air pollution, metabolic syndrome, and heart rate variability: the multi-ethnic study of atherosclerosis (MESA). Environ Health Perspect 2010;118:1406-11.

35. Schneider A, Hampel R, Ibald-Mulli A et al. Changes in deceleration capacity of heart rate and heart rate variability induced by ambient air pollution in individuals with coronary artery disease. Part Fibre Toxicol 2010;7:29.

36. Suh HH, Zanobetti A. Exposure error masks the relationship between traffic-related air pollution and heart rate variability. J Occup Environ Med 2010:52:685-92

37. Wu S, Deng F, Niu J, et al. Association of heart rate variability in taxi drivers with marked changes in particulate air pollution in Beijing in 2008. Environ Health Perspect 2010;118:87-91

38. He F, Shaffer ML, Li XA, et al. Individual-level PM P.. $_{2.5}$ exposure and the time course of impaired heart rate variability: the APACR Study. J Expo Sci Environ Epidemiol 2011:21:65-73.

39. Jia X, Song X, Shima M, et al. Acute effect of ambient ozone on heart rate variability in healthy elderly subjects. J Expos Sci Environ Epidemiol 2011:21:541-7.

40. Tsuji H, Venditti FJ, Manders ES, et al. Determinants of heart rate variability. J Am Coll Cardiol 1996;28:1539-46.

41. Zareba W, Nomura A, Couderc JP. Cardiovascular effects of air pollution: what to measure in ECG? Environ Health Perspect 2001:109:533-8.

42. Ballester F, Medina S, Boldo E, et al. Reducing ambient levels of fine particulates could substantially improve health: a mortality impact assessment for 26 European cities. J Epidemiol Community Health 2008;62:98-105

43. Kleiger RE, Miller JP, Bigger JT, et al. Decreased heart-rate-variability and its association with increased mortality after acute myocardial-infarction. Am J Cardio 1987:59:256-62.

44. Nolan J, Batin PD, Andrews R, et al. Prospective study of heart rate variability and mortality in chronic heart failure: results of the United Kingdom heart failure evaluation and assessment of risk trial (UK-Heart). Circulation 1998;98:1510-16.

45. La Rovere MT, Pinna GD, Maestri $\mathrm{R}$, et al. Short-term heart rate variability strongly predicts sudden cardiac death in chronic heart failure patients. Circulation 2003; 107:565-70.

46. Tsuji H, Larson MG, Venditti FJ, et al. Impact of reduced heart rate variability on risk for cardiac events. The Framingham Heart Study. Circulation 1996;94:2850-5. 
47. Rennie $\mathbf{K L}$, Hemingway $\mathrm{H}$, Kumari $\mathrm{M}$, et al. Effects of moderate and vigorous physical activity on heart rate variability in a British study of civil servants. Am J Epidemiol 2003;158:135-43.

48. Zulfiqar $\mathbf{U}$, Jurivich $\mathrm{DA}$, Gao $\mathrm{WH}$, et al. Relation of high heart rate variability to healthy longevity. Am J Cardiol 2010;105:1181-5

49. Patel M, Lal SKL, Kavanagh D, et al. Applying neural network analysis on heart rate variability data to assess driver fatigue. Expert Syst Appl 2011;38:7235-42.

50. Weber CS, Thayer JF, Rudat M, et al. Low vagal tone is associated with impaired post stress recovery of cardiovascular, endocrine, and immune markers. Eur $\mathrm{J}$ Appl Physiol 2010;109:201-11

51. Tak LM, Riese H, de Bock GH, et al. As good as it gets? A meta-analysis and systematic review of methodological quality of heart rate variability studies in functional somatic disorders. Biol Psychol 2009;82:101-10.

52. Brook RD, Franklin B, Cascio W, et al. Air pollution and cardiovascular disease. Circulation 2004;109:2655-71.

53. Pope CA, Burnett RT, Thurston GD, et al. Cardiovascular mortality and long-term exposure to particulate air pollution. Circulation 2004:109:71-7.

54. HEl. Understanding the Health Effects of Components of the Particulate Matter Mix: Progress and Next Steps. 2002.

55. Stone PH, Godleski JJ. First steps toward understanding the pathophysiologic link between air pollution and cardiac mortality. Am Heart J 1999;138:804-7.

56. Felber Dietrich D, Schwartz J, Schindler C, et al. Effects of passive smoking on heart rate variability, heart rate and blood pressure: an observational study. Int $\mathrm{J}$ Epidemiol 2007:36:834-40.
57. Mazzoli-Rocha F, Fernandes S, Einicker-Lamas M, et al. Roles of oxidative stress in signaling and inflammation induced by particulate matter. Cell Biol Toxicol 2010;26:481-98

58. Schwartz J, Park SK, O’Neill MS, et al. Glutathione-S-transferase M1, obesity, statins, and autonomic effects of particles - Gene-by-drug-by-environment interaction. Am J Respir Crit Care Med 2005;172:1529-33.

59. Baccarelli A, Cassano PA, Litonjua A, et al. Cardiac autonomic dysfunction: effects from particulate air pollution and protection by dietary methyl nutrients and metabolic polymorphisms. Circulation 2008;117:1802-9.

60. Park SK, O'Neill MS, Wright RO, et al. HFE genotype, particulate air pollution, and heart rate variability: a gene-environment interaction. Circulation 2006;114:2798-805

61. Romieu I, Tellez-Rojo MM, Lazo M et al. Omega-3 fatty acid prevents heart rate variability reductions associated with particulate matter. Am J Respir Crit Care Med 2005; 172:1534-40.

62. Chahine T, Baccarelli A, Litonjua A, et al. Particulate air pollution, oxidative stress genes, and heart rate variability in an elderly cohort. Environ Health Perspect 2007:115:1617-22.

63. Schulz H, Harder V, Ibald-Mulli A, et al. Cardiovascular effects of fine and ultrafine particles. J Aerosol Med 2005;18:1-22.

64. Wu C-f, Kuo I-C, Su T-C, et al. Effects of personal exposure to particulate matter and ozone on arterial stiffness and heart rate variability in healthy adults. Am J Epidemiol 2010;171:1299-309.

65. Shannon DC, Carley DW, Benson H. Aging of modulation of heart-rate. Am J Physiol 1987;253:H874-7.

\section{Heart alerts}

Sign up for our electronic table of contents alert and you will never miss new issues of Heart when published online. Stay ahead and up to date by visiting heart.bmj.com. 